Bauer, Susanne (2017): Radiation Science after the Cold War. The Politics of Measurement, Risk, and Compensation in Kazakhstan, in: Zvonareva, Olga, Evgeniya Popova, Klasien Horstman (eds). Health, Technologies, and Politics in Post-Soviet Settings; Navigating Uncertainty. Palgrave Macmillan.

\title{
CHAPTER 9. RADIATION SCIENCE AFTER THE COLD WAR. THE POLITICS OF MEASUREMENT, RISK, AND COMPENSATION IN KAZAKHSTAN
}

\section{Susanne Bauer}

Bio. Susanne Bauer is Associate Professor of Science and Technology Studies (STS) at the TIK Centre for Technology, Innovation, and Culture, University of Oslo. She has a background in environmental studies completed in Berlin and Odessa and holds a doctorate in public health from the University of Bielefeld. She held researcher and visiting positions at the Institute for Advanced Studies of Science, Technology and Society in Graz, Medical Museion, University of Copenhagen, Humboldt University Berlin and the Max Planck Institute for the History of Science, and a visiting professorship at Indiana University, Bloomington. Before moving to Oslo, she was junior professor in sociology of science at Goethe University, Frankfurt am Main.

\begin{abstract}
In the northeast of Kazakhstan more than 110 above ground nuclear explosions were carried out between 1949 and 1963. After the moratorium on atmospheric nuclear tests, underground nuclear testing was continued until 1989. This chapter follows the routes chosen by scientists and those responsible for public compensation programmes to navigate uncertainties of radiation-exposure in local communities around Semipalatinsk. It describes how, since the 1990s, research and compensation programmes have been negotiated and implemented in post-Soviet Kazakhstan, following decades of biomedical research during Soviet time. It shows how in the context of international collaborative projects, efforts to document long-term health effects stimulated innovations in epidemiological studies, exposure reconstruction, risk estimation, and radiation ecology. However, while negotiating compensation for local communities, most benefits of the innovative studies travelled to scientific practices in western countries, leaving global health disparities as they were.
\end{abstract}

'Vzryvaiut' ('They are blasting again'). It was often just one word by which people in the city of Semipalatinsk casually noticed that kitchen cupboards were trembling. As my interlocutors further recall, they had been accustomed to the occasional earthquake-like grumbling from the 'polygon', the Semipalatinsk test site, 
where underground nuclear tests were conducted until 1989. This was felt even about $200 \mathrm{~km}$ away from the test epicentres in Semipalatinsk city, with its population of more than 300,000 in the 1980 s. People living closer to the site in the nearby steppe villages had witnessed these events. Collective farm workers reported decades after atmospheric testing that they had seen the mushroom clouds and diseased sheep during the 1950s when nuclear tests were conducted above ground — at the time, the military had ordered them to never, ever talk about what they saw. While nuclear testing was done under secrecy, people were aware that there was some 'polygon', an experimental site, and that there were blasts. More details about exposure in adjacent areas only reached a broader public during the late 1980s after the 'glasnost' reforms and the formation of antinuclear movements. Substantial areas in the northeastern parts of the former Soviet Republic of Kazakhstan were affected by nuclear fallout from atmospheric testing (Balmukhanov, Gusev \& Balmukhanov, 2002). Between the 1950s and 1989, nuclear weapons testing was conducted and scientifically monitored by scientists and engineers in the atomic city of Kurchatov (also known as 'Semipalatinsk-21') located on the Semipalatinsk test site. The test site comprised an area of about $19,000 \mathrm{~km}^{2}$. The atomic science city had a changing population that reached more than 20,000 and, like other closed science cities in the Soviet Union, was known for providing good living standards. Most nuclear scientists and engineers stayed for a few years before moving back to Moscow; other scientific employees working in research institutes in Semipalatinsk travelled back and forth between Semipalatinsk city and the Kurchatov research centres for duty work. Physicists recall this as quite routine despite demanding night shifts; at the time, they saw this as necessary peacekeeping in the age of the Cold War. This first Soviet nuclear test site, founded in 1947, was officially closed in 1991 by the government of the Republic of Kazakhstan. 
Between 1949 and 1989, extensive atmospheric and underground nuclear testing was carried out on the Semipalatinsk nuclear test site in the steppe region of northeast Kazakhstan, less than $200 \mathrm{~km}$ from the city of Semipalatinsk (later renamed Semei). The test site had been constructed in 1947 and, during Stalinist times, the first nuclear test device was exploded there on August 29, 1949, at the order of General Lavrentyi Beria (Gordin, 2010). The weather conditions led to the formation of a radioactive cloud that moved to the east and north after the nuclear test, resulting in fallout deposition over areas in Kazakhstan and the Altai region. This was but the first atmospheric nuclear explosion; more than 110 above ground followed until a preliminary moratorium in 1963 . Underground testing was continued until 1989, with some of these below-surface nuclear tests resulting in leakage of radioactive gases. Reports by the Ministry of Atomic Energy and Ministry of Defence of the Russian Federation listed 456 explosions at the Semipalatinsk test site (Mikhailov, 1996). Similarly to the American nuclear tests on the Nevada test site and in the Pacific, nuclear tests were largely part of a military programme. Official documents also report about 40 experimental 'peaceful' nuclear tests that were framed as civil engineering projects, aimed at excavation for mining purposes and manipulation of river flows (Mikhailov, 1996).

The legacies of the nuclear testing remained after the official closure of the test site in 1991. The economic crisis after the breakdown of the Soviet administration and its public health system, particularly affected people in rural areas. Soviet institutions and collective farms closed, and people fully resorted to livestock smallholdings and informal economies. During the economic crisis with multiple currency reforms, salaries were delayed for months, and informal economies emerged not only in rural areas but also in post-Soviet urban centres. 
Nuclear testing has altered the lives of communities in the surrounding areas. It was concerns voiced by public health staff that led to the first investigations and followup, which began as early as the late 1950s. But the research on environmental and health effects in the area remained classified for decades. After the secrecy surrounding the radiation situation, what occurred in the early 1990s was often called an 'information boom'. While awareness of radiation issues increased, communities close to or on the test site were left on their own to cope with the fallout legacies in an economically precarious situation. Adjoining communities deal with and inhabit nuclear ecologies on a daily basis - and some reimagine their biologies as adapted or even immune to radiation (Stawkowski, 2016).

Biomedical research on radiation consequences entered the area with temporary research projects and state-funded national compensation programmes organised mass screening examinations. Yet at the same time, as in other post-Soviet countries, officials coined the concept of 'radiophobia', which further stigmatised already marginalised people and concerns about fallout exposure. During the post-Soviet years, the scientific assessment became increasingly co-shaped by Western actors, institutions, international agencies, and conversion programs, blending into local research and medical affairs (Bauer, Kalmbach \& Kasperski, 2017). With the science of fallout effects new actors, methods, and a new globalised mode of doing research entered the stage.

Anna Tsing (2005) has proposed the notion of friction to describe the encounters of economies, logics, and agendas in places where mutual understanding is not taken for granted. In Semipalatinsk, frictions occurred not only between the Western and Soviet traditions of doing science, but also between institutions, the state, nongovernmental organisations (NGOs), and between disciplines, as physicists, 
dosimetrists, physicians, epidemiologists, and sociologists were involved in the risk assessments. Nuclear science had made nuclear weapons possible in the first place, but science was also urgently needed in the assessment of the radiological situation. Often science is defined or defines itself by separating the scientific from the political. But, I will argue, the very scientific practises, methods and results do have politics, both in knowledge generation itself as well as in its consequences for everyday lives. What does it mean to do radiation risk research on the ruins of Cold War nuclear testing at a place like Semipalatinsk? This chapter explores routes taken by biomedical researchers and officials responsible for compensation programmes to navigate multiple uncertainties of fallout exposure among local communities on and around Semipalatinsk test site. It highlights implications of these choices for wellbeing of local communities and distribution of benefits associated with fallout science among actors involved.

As Olga Kuchinskaya (2013) has noted, radiation is 'twice invisible', both physically and in terms of the often black-boxed assessment techniques. In order to open up these invisibilities, I describe selected practises of risk assessment and provide examples of frictions that emerge when risk assessment frameworks are revised and innovated. I open up technical processes of knowledge production in order to better understand the tensions and 'regimes of imperceptibility' (Murphy, 2006) that govern the efforts to document fallout effects on health. The material I draw on is based on document analysis and published literature and on observations as a researcher in radiation epidemiology projects between 1997 and 2002 and further research stays and exchanges between 2009 and 2013. In what follows, I describe the ways in which global expertise entered Semipalatinsk studies during the 'transition period'. I then examine how scientific innovation has become entangled in local compensation matters in 
unexpected ways. As a whole, the chapter contributes to the understanding of how science, technology, and medicine are implicated in and produce politics, at times in unexpected ways.

\section{The Soviet nuclear programme and the quest for global nuclear expertise}

Cold War nuclear programmes profoundly altered lives and environments in several regions of the former Soviet Union. Beyond the better-known Chernobyl accident or the decades of plutonium production in Southern Urals nuclear facilities, the Semipalatinsk nuclear test site was one of the areas with substantial radiation legacies at the end of the Cold War. These nuclear geographies exhibit a striking symmetry on both sides of the Iron Curtain. For most of the sites in the closed worlds of the USSR, one can find a counterpart in the United States: The Nevada test site and the Semipalatinsk test site, and the Hanford plutonium production site in Richland, Washington, and the Mayak plant in Ozyorsk in the Southern Urals, were twin nuclear sites, indeed (Brown, 2013). The Soviet atomic programme had placed nuclear test sites in remote steppe lands of Central Asia and later also Novaya Zemlya in the Arctic Ocean, turning these regions into the nuclear backyard of the USSR. Key sites related to the atomic programme and military research were built in closed cities in Central Asia, including the Semipalatinsk test site and the closed science city of Kurchatov, named for the Soviet atomic scientist. Vast areas in Central Asia were shaped by other large-scale technology projects, including the diversion of rivers and creation of a settler workforce for projects of greening the steppe and turning the steppe areas into agricultural lands.

In the midst and as part of tremendous societal change, the Soviet nuclear test site was closed in 1991 and the social movement Nevada-Semipalatinsk that had protested 
against nuclear testing was met with recognition by the new Republic of Kazakhstan. With the closing of the test site, most Russian scientists moved to the Russian Federation and the technical archives and data were transferred to a military archive in Sergiev-Posad, near Moscow. The science city of Kurchatov lost most of its population: When I visited for the first time in 1998, nearly-abandoned science buildings and empty department stores bore witness to its better past. The facilities, including nuclear research reactors, became Kazakhstan's National Nuclear Center now being in charge of radiation monitoring on the test site. With a few exceptions within the test site, large areas have never been fenced; locals often crossed the open steppe lands. Moreover, with economic disruption, collecting remaining metal items that could be sold for recycling became a significant source of income.

After the dissolution of the USSR, the former Soviet republic of Kazakhstan became an independent member in the United Nations and its organisations. Because much of the scientific infrastructure and archives had been moved to the Russian Federation, the government of Kazakhstan called for international assistance in dealing with the nuclear legacies and taking safety measures (UN, 1998). The International Agency for Atomic Energy (IAEA) and the World Health Organization (WHO) held missions to the Semipalatinsk test site during the 1990s to assess the radiological situation (IAEA, 1998). By inviting international researchers to the site, the new independent state of Kazakhstan complemented the agenda of post-Soviet independence.

Efforts to assess the radiological situation included risk assessment of the present and the documentation of the past health consequences of fallout. The scientific means to investigate the effects on public health were epidemiological studies. Public health science attained an important function here in providing statistics on the extent of 
effects and the number of people at risk or suffering from the long-term consequences of fallout. After the call for assistance from the government of Kazakhstan and the adoption of UN resolutions, international agencies together with local health researchers began to undertake epidemiological studies. Their goal was to provide and clarify findings that could then be used in the policy processes that guide the allocation of resources to these populations. Public health knowledge is thus deeply intertwined with policy processes. Scientific risk assessment has taken on a key role in generating knowledge that informs these processes. In the contestations over sparse resources, international agencies and also increasingly the national institutions demanded proof of the effects of fallout before considering policy responses. Even if researchers at Semipalatinsk often insisted on having nothing to do and say on politics, they were entangled in politics from the beginning, both in the institutional collaborations as well as with the many stakes in these studies and in the decisions they were to take in the process of knowledge production: What counts as knowledge, and to what extent can there be a scientific consensus? What other connections and relations come into play in the transnational collaborations?

The initial rationale of Western funding was to gain insight into the radiological situation in known exposure areas including Chernobyl, Southern Urals and later also Semipalatinsk as well as to gain knowledge and secure monitoring of potential future radiation risks as a contribution to meet concerns over transboundary security. Western health scientists entered the scene a few years after radiological safety measures by nuclear scientists coordinated by IAEA but also by the US DOE (Department of Energy) to secure the shafts on the test site and to irreversibly prevent its future military use for nuclear testing. A further goal was to support the conversion of former military institutions and their researchers to non-military activities, supplementing the 
conversion and nuclear disarmament agreements negotiated in the late 1980s. International health projects in the late 1990s began with the goals of gathering existing data and embarking on a collaborative analysis with institutions in Kazakhstan (Bauer et al. 2013). At stake for Kazakhstan scientists and local communities was not only the scientific issue of a consensus on the deposition rates and their representation on fallout maps and health data charts, but also entitlement to compensation that would result from these representations. How did the entry of Western researchers committed to studying health issues take place and what approaches did they bring? In order to understand encounters and agendas, one needs to look more closely into knowledge and data practises in radiation epidemiology.

\section{'Learning from the Soviet radiation experience'. Aligning methodology and}

\section{human tragedy}

Cold War institutions and radiation science have played a key role not only in conducting nuclear tests, but paradoxically also in assessing the very consequences of nuclear fallout. The term 'biomedicine' itself developed from the research on the effects of radiation on life in the context of large-scale research infrastructure building in the nuclear programme and in information technologies that became part of state-funded large-scale research endeavours during the Cold War (Keating \& Cambrosio, 2003). Like in the US, on the Soviet side of Cold War science, there had been a busy field radiation research alongside the nuclear race. In Semipalatinsk, a radiation oncology clinic, the Dispensary No. 4, camouflaged as a 'brucellosis hospital', began its research into health effects in 1959 (Bauer, 2006). The Dispensary No. 4 diagnosed and treated cancer; staff annually examined groups of people exposed to fallout in the settlements, continually following up on them in collaboration with the public health services. Much 
of this research conducted in cancer epidemiology adhered to the Soviet tradition of epidemiology. While there was exchange between both sides of the Cold War through UN platforms and institutions such as WHO, public health research developed in different directions on both sides of the Iron Curtain. The introduction of analytic techniques that had developed in Western 'risk factor epidemiology' in particular did not fit with the research previously conducted in the USSR. In order to confirm that there was a radiation issue, Western public health researchers and international agencies demanded formats of proof according to the globally standardized study designs of analytical epidemiology. Local researchers were aware of the stakes for mitigation of the fallout consequences and also the needs of the affected rural communities. Some of them formed and aligned with NGOs to voice their concerns. While the generation of medical scientists trained during Soviet times held on to the research traditions at many medical schools in the Russian Federation and Kazakhstan, younger researchers were eager to embark on the new opportunities. The new collaborative projects faced the need to translate and reevaluate the already existing data with Western methods to secure their credibility and to match their proposals to the demands by funding agencies under new conditions.

Key to the requirement to do a state-of-the-art epidemiological study with an analytic design is the proof of a statistical association between radiation and health effects. To comply with the standards of epidemiological science and prove that the factor of interest is truly associated with the exposure, dose estimates at individual levels were needed. This is a routine methodological requirement of proof as established in Western epidemiology. In contrast, many epidemiological studies in the Soviet Union operated with area-based group estimates, which in the evidence hierarchies of epidemiology qualified as hypothesis-generating but not testing and thus 
not sufficiently proving an effect. Also, most metrics (post-)Soviet scientists used were different: for example, it was common to descriptively study the distribution and proportions of cancers and different causes of death and track the changes in this 'structure' of mortality and its changes over time; this was a different way of comprehending disease patterns and their changes over time. Contrary to Western formats, this was often done in absolute numbers (giving proportions) without age standardisation. Many of the results of Soviet risk assessments were not compatible with the standard study designs used by Western epidemiologists. Thus, most of the collaborative projects were translation efforts and accompanied by debates over the choice of metrics, standardisation, and study designs, including pertinent computer software.

The agendas Western researchers travelled with were yet different. What drew scientists from leading biomedical research centres to sites such as Semipalatinsk was what they called the 'unique opportunities' to learn from the Soviet radiation experience and the 'unique exposures of some of these populations', as researchers stressed in funding proposals and review articles (e.g. Burkart, 1996). Scientists were interested in these different kinds of exposures that could then be aligned with the existing studies in radiation risk science, first and foremost with studies of atomic bomb survivors in Hiroshima and Nagasaki. This study conducted first by the US and then jointly by the US and Japan in the aftermath of the atomic bombing of Hiroshima and Nagasaki was the largest study on radiation effects on humans at the time (Lindee, 1994). Its continued credibility — even reaching the status of being labelled the 'gold standard' is in its long span of follow-up and also a result of several decades of stabilisation work. The atomic bomb survivors study still is the core source of information for the United Nations Scientific Committee on the Effects of Atomic Radiation (UNSCEAR), 
established in 1955, which regularly compiles, updates and synthesises the study results. Decisions about which studies to include are justified through methods requirements. Risk estimates calculated from the Soviet studies would be quantitatively compared to findings in the follow-up of the A-bomb survivors of Hiroshima and Nagasaki and cohorts of environmentally, occupationally, and medically exposed groups under epidemiological monitoring, for example, nuclear workers.

Because global radiation dose limits were based on extrapolations from the high external dose studies of Hiroshima and Nagasaki, European Union and US researchers hoped that the studies of Soviet nuclear legacies would add empirical observations at different doses and radiation qualities. In this way, like the studies in Japan, epidemiological work would transform the 'Soviet radiation experience' into a universalised resource to inform science-based knowledge of radiation. Semipalatinsk was seen as 'high risk-high potential' project for radiation biologists to secure more data relevant to debates they were involved in at home. As an example of how this translates into 'homeland matters' elsewhere, it was argued that 'findings are relevant to the current debate over how to protect people from chronic low-dose radiation near some of the DOE sites that represent the U.S.'s nuclear legacy' (Stone, 2002).

The objective of deriving risk estimates from exposed populations led to specific prioritisation in the joint projects. As a first step, researchers began compiling an inventory of exposure and health data, the kinds of data needed for radiation epidemiology. Exposure data, that is, dosimetry, had formed as its own subfield within 'radiation protection research' and 'health physics', measuring and monitoring radiation doses following regulatory dose limits for an annual level or lifetime exposure. In epidemiological studies, however, this information is used to test and estimate the association between the 'exposure' and the 'disease' outcome. Thus, data 
are translated from individuals to the population level. These calculations are done within a 'model-and-test system' that is constructed from the exposure and health data. This system consists of the empirical data (a file retrieved from the project database) and statistical modelling and analysis programmes. Compiling data and securing completeness of exposure and health records in a database is fundamental in creating the model-and-test system for the Semipalatinsk case. 'Exposure' denotes the radiation dose accumulated over time and 'disease' is the rate of cancer in exposed population groups. By entering these data into specialised computations (logistic regression models), epidemiologists derive risk estimates. As a rule, these metrics, which in radiation epidemiology measure excess relative risks, are compared to findings from studies of other radiation exposures, such as studies of atomic bomb survivors, radiation therapy patients, and nuclear workers. In this way, the Semipalatinsk data would be compared with risk estimates in atomic bomb survivors followed up by the Life Span Study (LSS). Risk estimates derived from the populations under study would in the long-term become part of radiation risk knowledge collected by UNSCEAR and by national boards that oversee standardisation of research methods and lab techniques.

While associations between radiation and cancer are in principle undisputed, there is controversy with respect to the strength of their association and to the low dose risks and effects other than cancer. In contrast, cardiovascular health effects have been shown in the follow-up studies in the Japanese atomic bomb survivors only recently. Moreover, the shapes of dose-response curves of for instance radiation-related cancer are always also political, as they matter again in everyday lives, by categorising an individual's health and exposure status in relation to a population or subpopulation. These have been controversial in the lower dose, and therefore researchers were always eager to test empirically whether a threshold for adverse effects existed and if so, the 
shape of the dose-response curve. The political dimensions of such abstractions can be traced deep into the very scientific debates themselves. Historian of science Robert Proctor has pointed to the different versions for the low-dose range as the politics of dose-response curves, distinguishing an 'environmental/bureaucratic' shape (linear, no threshold), an 'industrial/apologetic' shape (linear with threshold), a 'hormetic' shape (beneficial at low doses), and an 'environmental activist' (supralinear) shape of this curve (Proctor, 1995: 162).

In sum, to derive empirical dose-response data from Semipalatinsk follow-up, Western researchers emphasised gleaning individualised dose estimates. Epidemiologists collaborated with dosimetrists to secure valid data that they could use in their calculations. Sometimes, studies would have to wait for intercomparisons, because only a validated and generally accepted dosimetry system would be the basis for the recognition of epidemiological findings. Many dose reconstruction techniques relied on environmental samples and thus area-based group estimates and did not give data on the individual exposure. It was because of this methodological aspect that epidemiologists placed the new developments in biodosimetry as an innovative method for the reconstruction of individual doses high on their agendas.

\section{Technological innovation in the model-and-test system: Biological dosimetry}

To improve the database for purposes of risk assessment, new dosimetric techniques moved to centre stage in the efforts to generate knowledge that would meet international standards. This was a process that did not occur without generating friction. To further zoom into and locate the politics of scientific practises and innovations in radiation risk assessment, I focus on one example: a molecular biodosimetry technique introduced to reconstruct radiation doses due to fallout. Let's 
take a closer look at the cytogenetic method fluorescence in situ hybridization (FISH), a spin-off technique of genomics that was applied in Semipalatinsk to examine radiation-induced chromosome alterations (Stephan, Pressl, Koshpessova \& Gusev, 2001; Salomaa et al., 2002; Bersimbaev et al., 2002). FISH enables colourful visual display of chromosomes and translocations of parts on the screen of a microscope. The method is also called chromosome painting, because the fluorescence marking is a technique to make visible translocations of chromosome parts during cell division. From the number and kinds of translocations, researchers calculate the radiation dose of the cells examined by comparing the results with a calibration curve. To estimate the dose based on the translocation counts, each laboratory initially developed its own, labspecific calibration curve for dose dependence, using irradiated cells with a defined dose. Yet the stability of translocations over time, together with other methodological issues, still needed to be evaluated and the results validated against other techniques of dose reconstruction.

Studies of chromosome damage in human blood cells as such were not new but drew on established methods of conventional cytogenetics known as karyotyping (Chadarevian, 2014). The technique was also used in Soviet post-Lysenko biology, for instance at the Institute of Medical Genetics at the Soviet Academy of Medical Science (Bauer, 2014). ${ }^{2}$ Regarding Semipalatinsk studies, Soviet medical scientists had achieved that the Soviet Ministry of Health issued a study on fallout exposures in 1989 (Balmukhanov et al., 2002), including cytogenetic analysis of human blood samples, collected from three groups: people living in settlements close to the test site, students at the Medical College who had recently moved to the area, and students and faculty born in Semipalatinsk city. The samples were shipped to the Institute of Medical Radiology, Obninsk, near Moscow, for cytogenetic analysis, which confirmed 
increased frequencies of chromosome aberrations for students from settlements near the test site (Sevankaev et al., 1995). Differently from the measurement of dose pursued by the international projects, local scientists used chromosome alterations as a means of documenting the effect of exposure, much in line with other clinical effects. They compared rates in the exposed areas adjacent to the test site with areas outside known fallout trajectories (Shevshchenko et al., 1995; Rozenson, Gusev, Hoshi \& Satow, 1996):

In residents exposed to $80 \mathrm{cSv}$ chromosomal aberrations were encountered in $73.7 \%$ of the investigated persons. The percentage of aberrant cells per individual ranged from $2 \%$ to $7 \%$. In this exposed group, too, the frequency of chromosomal aberration, percentage of aberrant cells per individual, number of pair fragments and dicentrics were significantly higher as compared to the control. (Rozenson et al., 1996: 139-140)

Documentation of radiation effects by examining chromosome aberrations was also carried out by the Almaty-based Republican Research Center for Maternal and Children's Health Protection, which usually examined chromosome aberrations in prenatal diagnosis (Sviatova, Abildinova \& Berezina, 2001, 2002). Others, including Russian scientist Yuryi Dubrova, conducted studies on genetic alterations over several generations among exposed families both in Chernobyl and Semipalatinsk, documenting transgenerational effects of radiation exposure (Dubrova et al., 2002).

Similarly, the goal of the biodosimetrists working for epidemiological risk assessment projects was to establish a system that measured molecular markers in 
human blood cells and to use this not as an effect but rather as a marker to quantify radiation dose at the individual level. This would then be the exposure data tested for an association with disease:

Assuming translocation stability in peripheral blood lymphocytes over several decades, these findings suggest that on average, the magnitude of exposure of this cohort in the Semipalatinsk area has been considerably smaller than that reported in the literature. Previously reported doses of the order of $1-4.5$ Gy (mean 2.9 Gy in the $\mathrm{P}(0)$ generation) cannot be confirmed by the present data. (Salomaa et al., 2002: 591)

The findings summarised here question the dose estimates in previous reports based on a new technique, while also stating the assumptions of this claim that there is a stability of translocations over decades. In these settings, the human body is rendered not only as 'at risk' due to fallout, but as a dosimetric memory in which radiation inscribes itself, similar to the dosimeter device carried by nuclear workers. With biodosimetry, chromosome aberrations have become a marker in a person's cells that would be recognised as sufficient proof. The difference between the two approachesclinical marker versus dose estimation—seems perhaps a technical detail, but this small shift is relating fallout matters in a very different way. While the former examines potential health effects, the latter, at least as a first step, questions the reality of exposure and puts to test whether there will indeed be a health effect that can be causally linked to the exposure. 
While acknowledging the uncertainties in the method for determining radiation doses obtained decades ago, Western researchers considered a classic marker, dicentrics (one type of chromosome aberrations), suitable for detecting 'hallmarks of exposure to ionizing radiation' (Testa et al., 2001) and thus used it in the validation studies. The EU-funded project stated its objective in terms of 'verify(ing) the hypothesis of existing contamination' (Testa et al., 2001). In some of these documents, it becomes clear that at the core of the concern was the credibility of the Western scientists to their own research communities. At stake were different things for an international scientific project and for the research subjects under study who needed support from the public health infrastructure.

Cytogenetics used for biodosimetry also faced many practical problems, such as the transportation of blood samples, storage, and road conditions during cold winters and hot summers. Samples needed to get to the laboratory from remote areas within one or two days to start preparation for chromosome analysis. FISH reagents were costly, and therefore the method was not applicable to large-scale population studies. Instead, they were framed as a validation tool for dose estimates calculated by other methods. However, the techniques were also sensitive to small variations in chemicals and procedures, and findings were hardly comparable between different labs. Despite the standardisation and increasing automation of counting in the analyses, qualitative assessments remained important for the study of chromosome aberrations, for example when it came to particularly damaged singular cells ('rogue cells') that were difficult to standardise for population-level studies yet still interpreted in clinical contexts as likely signs of radiation damage. Thus, careful cytogenetic work does not always lend itself easily to developing a method that can be a tool readily applied in a standardised and robust way. The assessment and interpretation requires experience and practical 
knowledge, rather than just formalising single markers into a dosimeter technology that can simply be read and prove a dose and thereby entitlement to compensation.

The study of cell damage and environmentally induced chromosomal alteration has come to be rather troubling in terms of how this becomes relevant to the local communities and how they might influence government funding policies. Even though the advent of new biodosimetry techniques promised a clarification of the situation, the actual use of the technology also produced new technical questions to be resolved to the end of making the model-and-test system work. Thus, Semipalatinsk became also a test site, an experimental system, for the development of new dosimetry techniques. As often in experimental systems, emerging results added more questions than answers: Is the measurement system sensitive and able to detect exposure-related chromosomal alterations if they are there? How can the effects of time in the system be validated and estimated? Conventional cytogenetic counts of chromosomal change work well only shortly after the exposure. The refinement of the dosimetry data in the model-and-test system aimed at providing a means to detect chromosome damage years after the exposure took place. This was part of optimising and enhancing the experimental model-and-test system, because much of these data were already collected and then compiled for evaluation.

\section{The (uneven) circulation of knowledge and benefits. How science is political}

Dosimetry research circulated the samples from Semipalatinsk beyond the former Soviet research labs in Almaty, Moscow, Obninsk, and Minsk. Making their way into Western radiobiology labs_-to Italy, Helsinki, Munich, and Oak Ridge, as well as to Hiroshima in Japan, blood samples travelled routes to places that were inaccessible to their donors from the Kazakhstan villages. To the local communities, the transnational 
journeys of biological materials were both hope and threat, as the outcome in terms of recognition of exposure were beyond their influence. Due to the inconclusive results of biodosimetric studies, meetings called by the WHO stressed the need for further methods standardisation in order to 'solve' the dosimetry issue:

Previous publications cited external doses of more than 2 Gy to residents of Dolon while an expert group assembled by the WHO in 1997 estimated that external doses were likely to have been less than 0.5 Gy. [...] External dose estimates from calculations based on sparse physical measurements and bio-dosimetric estimates based on chromosome abnormalities and electron paramagnetic resonance from a relatively small sample of teeth do not agree well. The physical dose estimates are generally higher than the biodosimetric estimates (1 Gy or more compared to 0.5 Gy or less). (Simon, Baverstock, \& Lindholm, 2003: 718)

Biodosimetric studies, after a few years of laboratory intercomparisons and measurements, indicated lower doses than those dose estimates resulting from physical methods to calculate deposition. For the people living close to the test site, the stakes in this were high, and international assessments concluded that cumulative exposure were much lower than Kazakhstan scientists had calculated.

In a review of the state of the art in biodosimetry, radiation biologist Léonard and colleagues summarised: 
Biological dosimetry has serious limitations exactly for situations where the need for information is most urgent. It renders its most useful results when an individual has been exposed to a rather homogeneous high-level radiation over a short time interval, i.e. accidents at high-intensity radiation devices. (Léonard, Rueff, Gerber \& Léonard, 2005: 448)

Innovations in biodosimetry could not solve the exposure data problem, nor what was at stake locally-rather they brought new uncertainty, methodologically and in terms of benefits. For a few years, though, the former Soviet nuclear polygon operated a test site for biological dosimetry to test and prove its usefulness for risk assessment. Rather than settling the tensions and contentions about the degree of exposure, as had been hoped for, it was the fallout that became a testing ground for new molecular tools that would determine individual radiation dose.

The 'Law on the Social Protection of Citizens Exposed due to Nuclear Tests at the Semipalatinsk Nuclear Test Site' of the Republic of Kazakhstan had been adopted in 1992. However, for economic reasons, it was not implemented but put on hold for several years. The law foresaw that people living during the atmospheric nuclear testing in different areas of the Semipalatinsk region were entitled to one-time payments and a number of 'lgoty' (reduced prices for gas and electricity, free health care and other public services). These payments and entitlements depended on degree of exposure, based on geographic, district-based dose estimates and age at exposure and confirmed residency during the time of atmospheric nuclear testing. The implementation of this had been postponed several times, and the claims that could be made based on dose certificates were perceived as minor if not symbolic. Yet, they did make a difference 
and did matter to a considerable part of the population, depending also on their exposure category.

Resources of the national programme trickled down only slowly to the exposed rutal areas where the support was most needed. If international results found that exposures were in the range of permissible doses in other countries, this would interfere with the local assessments in the Kazakhstan law on compensation. In fact, a certified radiation dose was a socially significant number for affected people, because they were able to claim benefits according to the corresponding group in the compensation programme. In this way research, even conducted as basic science or methodological validation, comes to impact everyday lives — at times despite other intentions.

While the study of biomarkers of exposure followed the demands of epidemiologists, chromosome painting challenged the conceptual frameworks of compensation policies: 'It is anticipated that the addition of molecular parameters to the population-based studies will allow determination of real rather than calculated risks' (Akleyev, 2000). Thus the calculated risks and their safety margins (which were more expensive to governments) would be replaced by real risks - and what is considered real is the trace detectable in the body in terms of chromosome damage. Biodosimetric results were envisioned to distinguish, through 'the study of mechanisms and biomarkers of radiation-induced alterations', between the 'notion of an exposed versus an affected individual' (Akleyev, 2000). A new kind of boundary is being drawn here: The 'exposed individual' would no longer be entitled to compensation or 'Igoty', which would be restricted to the 'affected individual' diagnosed with a disease from a specific list of diagnosis recognised to be associated with radiation. As a DOE representative stressed, this was 'of immense social and economic significance' (Neta, 2000) for the regions and governments. Here an economic consideration joins the 
epidemiological quest for individual doses. What is at stake here is resources and, linked to this, different modes of allocating compensation: compensation for exposure (as in some instances in the former Soviet Union with one-time payments) versus compensation for disease (as in the US Radiation Exposure Compensation Act). Some regulations even demand proof of causation and apply individually computed causation probabilities (for example the recognition of occupational diseases, as practised in Germany). In sum, compensating for exposure reflects a state-benefit environmental justice model, while compensating for disease is a more insurance-based model. The models distribute the burden of proof differently between the state institutions responsible for the exposure on one hand and the individuals at risk of exposure-related disease on the other. One of my interlocutors, a scientist working in Kazakhstan, stressed that each time the dose estimates are lowered, problems mount for those exposed. In this specific situation, biodosimetry results came to perform to divert responsibility away from the state and normalise the fallout issue.

Western science designed the health studies in a way that used the data retrospectively, mining the Soviet radiation experience in a type of extractive mode, this time knowledge extraction. Even when it is not a retrospective but prospective health study among people who are now alive, the benefits of analytical epidemiology will have little to return to those who underwent, and suffered from the consequences of, radiation exposure. If there are benefits, they are delocalised and will rather travel to countries affluent enough to iteratively adapt their radiation protection standards with new findings that come from the analysis of the 'Semipalatinsk radiation experience'. It is an alignment of optimising radiation protection that goes together with knowledge moved away from exposed communities and taken to global platforms of radiation knowledge. Some researchers see these data extractions as 'scientists' duty to study 
exposed populations', others as problematic endeavour that lacks reciprocity. At the same time, radiation protection knowledge builds on deriving knowledge from exposed and disadvantaged populations that is used to optimise the lives of others, which raises issues of the distribution of benefits.

Adriana Petryna (2006) has analysed the Chernobyl compensation system of post-Soviet Ukraine as a specific type of relation between people affected by radiation and the state. In this mode of 'biological citizenship', as she termed it, people used their exposed biologies to claim their rights from the state. The schemes of compensation by 'lgoty' (benefits and price reductions) in Kazakhstan were similar to those in some other post-Soviet countries. Yet it was only after building the new capital of Astana on the former city of Tselinograd that the inflow of capital from the state's oil adventures a decade after closing the test site began trickling down to the exposed regions. In Kazakhstan, the law on compensation became fully effective only after pipelines to Russia and China secured the export of oil. Oil fields under development brought a continuous influx of international capital as well as money to national oil companies and shares in the oil consortia. After all, it was also money of a 'petrostate' (Goldman, 2010) used to establish some basic infrastructure of medical screening and rehabilitation programmes for the exposed populations. But there are also other things already emerging at the same time: the beginning of a new nuclear programme. Not long after closing the Semipalatinsk nuclear test, Kazakhstan embarked on a different nuclear endeavour, large-scale uranium mining. By 2009, the Republic of Kazakhstan was the world leader in uranium export.

The national compensation programme in Kazakhstan was similar to the benefits in other Soviet and post-Soviet rehabilitation programmes. Its risk zonings were connected to available data compiled with a view toward mitigating the radiological 
situation. The law was developed at a specific window of opportunity when a new state and its government were willing to break with this part of the Soviet past and new nation building included recognition of victims of the past. In contrast, international research projects brought with them a different frame of reference and set of practises, which led to efforts to build model-and-test systems rooted in the tradition from which they came. Compensation as a mode of mitigation has been more common in postSoviet than in Western countries. Western countries tend to regulate similar issues in different, perhaps less direct ways, some through insurance systems rather than direct compensation payments and general price reductions. What Petryna called biological citizenship may be characterised as a (post-)Soviet version of attempts to address past injustice. The ways in which compensations operate also depend on their distribution and accessibility. Possibilities to claim benefits are much more limited for those who live more remotely, with transportation to the state institutions from the steppe being expensive.

The very practise of science does have politics and an impact on these debates, when researchers design exposure registries, decide cutpoints for exposure status, introduce dosimetry techniques, assess risks of population groups, and determine inclusion or exclusions in health studies; the study results based on these decisions will be used to inform and be translated into policies and public health planning. That there is myriad of small decisions to be taken in risk assessment in modelling in science becomes visible when the distributed scientific processes are more closely examined. Engaging in scientific knowledge production, willingly or not, is a relational practise that has consequences in the politics of everyday life. 


\section{Conclusion}

Scientific endeavours conducted during the early post-Soviet years have transferred Western scientists, their methods, and their agendas to the fallout areas of Kazakhstan. In parallel, they brought human blood and environmental samples from the fallout area to Western nuclear laboratories. Those travels did not take place without friction with the ways in which fallout matters had come to be addressed in the local compensation programmes. First, the intervention by Western scientists produced a version of documentation that translated 'the Soviet radiation experience' into a generalised model-and-test system of radiation knowledge. Second, these kinds of projects intervened in previous assessments in ways that called into question local assessments and measures. Third, local researchers, it seemed, had to take sides or, more often, become experts in performing in and for both science systems, while navigating different science policies, funding schemes, and bureaucracies. Although a few scientists from Kazakhstan managed to embark on international careers, the benefits from such research did not travel in both directions in the same way. Benefits from fallout science moved mainly in one direction: to be translated into a knowledge repository that informs global radiation protection guidelines. These are of use in a more abstract sense to more affluent countries, but leave affected communities, from which the knowledge is derived, largely without direct benefits. In contrast to the era of nuclear tests in Semipalatinsk, there is no longer the grumbling of underground nuclear tests today, but there are still-lingering nuclear legacies. Even the science of damage evaluation can come as an aftershock rather than as mitigation to the precarious situation in the affected communities. Analysing these frictions and unevenly distributed benefits helps us understand how the Cold War has undergirded knowledge of radiation protection. Understanding the infrastructures and politics of risk 
assessment may provide tools to make a difference with respect to mitigating global health disparities.

\section{Notes:}

${ }^{1}$ The terms 'transition' and 'transitology' in post-Soviet studies beg the question of from where to where this transition was supposed to take place. Post-Soviet transition processes have been said to have moved from state to corporate realms at first and recently back to the state (Goldman, 2010) in the Russian Federation and in Kazakhstan.

${ }^{2}$ During the Cold War fallout debates, both Western and Soviet radiation biologists and geneticists measured mutation rates in human cells irradiated in the laboratory at defined doses (Luchnik et al., 1976; Sevankaev et al., 1995). With regard to chromosomal damage, Soviet medical geneticists and radiation biologists wrote about the dangers of radiation and nuclear war (Bochkov, 1966, 1983). In the 1970s, cytogenetic techniques to detect chromosomal alterations (e.g. by karyotyping) became widely used in prenatal diagnosis.

\section{References}

Akleyev, A.V. (2000). Implications of biological markers of irradiation, exposure dose, and radiation induced effects for radiation medicine. Proceedings of the International Symposium 'Chronic Radiation Exposure: Possibilities of biological indication' (pp. 80-81). Chelyabinsk.

Balmukhanov, S.G., Gusev, B.I. \& Balmukhanov, T.S. (2002). Radioactivity and population health status around the Semipalatinsk Nuclear Test Site. Almaty. 
Bauer, S. (2006). The local health impact of atmospheric nuclear testing. Cancer epidemiology in areas adjacent to the Semipalatinsk nuclear test site, Kazakhstan. Frankfurt am Main/New York: Peter Lang.

Bauer, S., Gusev, B, Belikhina, T., Moldagaliev,T. \& Apsalikov, K. (2013). The legacies of Soviet nuclear testing in Kazakhstan fallout, public health and societal issues. In: Oughton, D. \& Hansson, S.-O. (Eds.) Social and Ethical Aspects of Radiation Risk Management, Elsevier Science, 239-258.

Bauer, S., Kalmbach, K. \& Kasperski, T. (2017) From Pripyat to Paris, from grassroots memories to globalized knowledge production: the politics of nuclear fallout. In: L. McDowell (Ed.): Nuclear Portraits (pp.149-189). Toronto: University of Toronto Press.

Bersimbaev, R.L., C, Dubrova, Yu.E., Hulten, M., Koivistoinen, A., Tankimanova, M., Mamyrbaeva, Z., Djansugarova, L., Mustonen, R. \& Salomaa, S. (2002) Minisatellite mutations and biodosimetry of the population living close to the Semipalatinsk nuclear test site. In Lindholm, S.; Makar, B. \& Baverstock, K, (Eds). Workshop on dosimetry of the population living in the proximity of the Semipalatinsk atomic weapons test site. STUK Report A 187 (pp. 40-48) Helsinki: STUK.

Bochkov, N.P. (1966). [Cytogenic effects of radiation in man, in Russian]. Medical Radiology (Moscow) 11 (12), 45-52.

Bochkov, N.P. (1983). [Genetic consequences of nuclear arms use, in Russian]. Bulletin of the Academy of Medical Sciences of the USSR 4, 36-41.

Brown, K. (2013). Plutopia: nuclear families, atomic cities, and the great Soviet and American plutonium disasters. Oxford University Press. 
Burkart, W. (1996). Radioepidemiology in the aftermath of the nuclear program of the former Soviet Union: unique lessons to be learnt. Radiation Environmental Biophysics 35: 65-73.

Dubrova, Yu., R. I. Bersonbaev, L. B. Djansugurova, M. K. Tankimanova, Z. H. Mamybaeva, R., Mustonen, C., Lindholm, M., Hulten, S. \& Salooma, S. (2002). Nuclear weapons tests and human germline mutation rate. Science 295, 1307.

Goldman, M. (2010). Petrostate: Putin, power, and the new Russia. New York/Oxford: Oxford University Press.

Gordin, M. (2010). Red cloud at dawn. Truman, Stalin, and the End of the Atomic Monopoly. New York: Farrar, Straus \& Giroux.

IAEA (1998). Radiological conditions at the Semipalatinsk nuclear test site, Kazakhstan. Preliminary. Report and Further Recommendations. Vienna: IAEA. Keating, P. \& Cambrosio, A. (2003). Biomedical platforms. Realigning the normal and the pathological in late-twentieth-century medicine. Cambridge MA: MIT Press.

Kuchinskaya, O. (2013). Twice invisible: formal representations of radiation danger. Social Studies of Science, 43, 78-96.

Leonard, A., Rueff J., Gerber, G.B. \& Léonard, E.D. (2005). Usefulness and limits of biological dosimetry based on cytogenetic methods. Radiation Protection Dosimetry 115, 448-454.

Lindee, S. (1994). Suffering made real. American science and the survivors at Hiroshima. Chicago: University of Chicago Press.

Luchnik, N.V. \& Sevankaev, A.V. (1976). Radiation-induced chromosomal aberrations in human lymphocytes. I. Dependence on the dose of gamma-rays and an anomaly at low doses. Mutation Research 36 (3), 363-378. 
Mikhailov, V. (1996). USSR nuclear weapons tests and peaceful nuclear explosions 1949 through 1990. Moscow: Ministry of the Russian Federation for Atomic Energy, The Ministry of Defense of the Russian Federation.

Murphy, M. (2006). Sick building syndrome. Environmental politics, technoscience and women workers. Durham: Duke University Press.

Neta, R. (2000). The promise of molecular epidemiology in defining the association between radiation and cancer. Proceedings of the International Symposium 'Chronic Radiation Exposure: Possibilities of biological indication’ (pp. 44-45), Chelyabinsk.

Petryna, A. (2005). Life exposed: biological citizens after Chernobyl. Priceton: (Princeton University Press.

Proctor, R.N. (1995). Cancer wars. How politics shapes what we know and don't know about cancer. New York: Basic Books.

Rozenson, R., Gusev, B.I., Hoshi, M., \& Satow, Y. (1996). A brief summary of radiation studies on residents in the Semipalatinsk area 1957-1993. Proceedings of the Nagasaki Symposium, Radiation and Human Health (pp. 127-146), Nagasaki.

Salomaa, S., Lindholm, C., Tankimanova, M.K., Mamyrbaeva, Z.Zh., Koivistoinen, A. Hultén, M., Mustonen, R., Dubrova, Yu., \& Bersimbaev, R.I. (2002). Stable chromosome aberrations in the lymphocytes of a population living in the vicinity of the Semipalatinsk nuclear test site. Radiation Research 158, 591-596.

Sevan'kaev, A.V., Ankina, M.A., Golub, E.V., Zhloba, A.A., Zavitaeva, T.A., Kozlov, V.M., Mikhailova, G.F., Moiseenko, V.V., Podyshkina, O.V., Potetnya, O.I. \& Pyatenko, V.S. (1995). [The results of cytogenetic studies of persons from the 
settlements adjacent to the Semipalatinsk testing ground, in Russian]. Radiatsionnaia Biologiia. Radioekologiia 35, 596-607.

Shevchenko, V., Snigirieva, G.P., Suskov, I.I., Akayrva, A.E., Elisova, T.N., Iofa, E.L., Nilova, I.N., Kostina, L.N., Novitskaya, N.N., Sidorova, V.F. \& Nazins, E.D. (1995). [The cytogenetic effects among the Altai region population exposed to ionizing radiation resulting from the Semipalatinsk nuclear tests, in Russian]. Radiatsionnaya Biologiia. Radioekologiia 35, 588-591.

Stawkowski, M. (2016). "I am a radioactive mutant." Emergent biological subjectivities at Kazakhstan's Semipalatinsk Nuclear Test Site. American Ethnologist Vol. 43, No. 1, pp. 144-157.

Stephan, G., Pressl, S., Koshpessova, G. \& Gusev. B.I. (2001). Analysis of FISHpainted chromosomes in individuals living near the Semipalatinsk nuclear test site. Radiation Research 155, 796-800.

Simon, S.L., Baverstock, K.F. \& Lindholm, C. (2003). A summary of evidence on radiation exposures received near to the Semipalatinsk nuclear weapons test site in Kazakhstan. Health Physics 84, 718-25.

Stone, R. (2002). Genetics. DNA mutations linked to Soviet bomb tests. Science 295 (5557), 946.

Sviatova, G.S., Abil'dinova, G.Zh. \& Berezina, G.M. (2001). The frequency, dynamics and stucture of genetic malformations in populations under long-term exposure to ionizing radiation. Russian Journal of Genetics 37, 1696-1704.

Sviatova, G.S., Abil'dinova, G.Zh. \& Berezina, G.M. (2002) Results of a cytogenetic study of populations with different radiation risks in the Semipalatinsk region. Russian Journal of Genetics 38 (3), 376-382. 
Testa, A., Stronati, L., Ranaldi, R., Spanò, M., Steinhäusler, F., Gastberger, M., Hubmer, A., Ptitskaya, L., Akhmetov, M. (2001). Cytogenetic biomonitoring carried out in a village (Dolon) adjacent to the Semipalatinsk nuclear weapon test site. Radiation Environmental Biophysics 40, 125-129.

Tsing, A. L. (2005). Frictions. An ethnography of global connection. Princeton: Princeton University Press.

United Nations General Assembly (1998), International cooperation and coordination for the human and ecological rehabilitations and economic development of the Semipalatinsk region of Kazakhstan. Report of the Secretary General, 23 September 1998 A/53/424. New York. 